\title{
Overcoming Learning Time And Space Constraints Through Technological Tool
}

\author{
Nafiseh Zarei (Corresponding author) \\ School of Language Studies and Linguistics, Faculty of Social Sciences and Humanities, Universiti Kebangsaan Malaysia \\ E-mail: nafiseh_zarei@yahoo.com \\ Supyan Hussin \\ School of Language Studies and Linguistics, Faculty of Social Sciences and Humanities, Universiti Kebangsaan Malaysia \\ E-mail: supyanukm@yahoo.com \\ Taufik Rashid \\ School of Public Administration, Universiti Kebangsaan Malaysia \\ E-mail: taufik@ukm.my
}

Doi:10.7575/aiac.alls.v.6n.4p.151

Received: 01/04/2015

URL: http://dx.doi.org/10.7575/aiac.alls.v.6n.4p.151

Accepted: 07/06/2015

\begin{abstract}
Today the use of technological tools has become an evolution in language learning and language acquisition. Many instructors and lecturers believe that integrating Web-based learning tools into language courses allows pupils to become active learners during learning process. This study investigate how the Learning Management Blog (LMB) overcomes the learning time and space constraints that contribute to students' language learning and language acquisition processes. The participants were 30 ESL students at National University of Malaysia. A qualitative approach comprising an open-ended questionnaire and a semi-structured interview was used to collect data. The results of the study revealed that the students' language learning and acquisition processes were enhanced. The students did not face any learning time and space limitations while being engaged in the learning process via the LMB. They learned and acquired knowledge using the language learning materials and forum at anytime and anywhere.
\end{abstract}

Keywords: learning time, learning space, learning management blog

\section{Introduction}

With the significant entry of technology, the traditional way of English teaching and learning had considerably changed. Technology has made so many opportunities available to make teaching and learning interesting. In addition, with the help of technology, teaching and learning may become more productive in terms of improvements and enhancements. Therefore, technology is one of the most important drivers of both social and linguistic changes. Today, accessing technology can help learners learn language even outside the classroom without teacher's attendance. In other words, with the help of technology and integrating social networks into language classes, students would be able to be involved in language learning and acquisition processes continuously at anytime and anywhere.

Blog, which is one of the internet media, can be a kind of language learning platform where students can interact with each other by sharing ideas, experiences and thoughts with no learning time and space boundaries. Students can make use of the language learning materials even though they are not in the classroom. Supyan et al. (2009) believed that "unlike the face-to-face discussion in the classroom that is limited by learning space and time, e-Forums allow teachers and learners to interact with one another outside of the four walls and specified time".

Various technological tools can be integrated as tools or platforms in learners' language learning. "Within L2 contexts, blog provides an alternative to writing assignments that would normally be presented to the instructor. The chronological ordering of blog entries creates for each student an archive of their personal work that they can, and do, revisit and reflect upon (Thorne and Payne, 2005)". A wide number of researchers (Duber 2002; Campbell 2003; Downes 2005; Brian 2006) have indicated that the potential of synchronous Web 2.0 tools is represented by the opportunity provided to learners to be involved in outside classroom activities where they learn through interaction and connectivity. This potential even more is realized especially when they are applied to traditional classroom situations where printed materials or textbooks represent the only source for language learning and language acquisition and teachers are the facilitators. Moreover, these technological tools play a role in enhancing ESL students' learning motivation, autonomy, attitude and even general language learning performance (Kabilan et al. 2010; Mazman and Usluel 2010; Pasfield-Neofitou 2011).

The application of blogs to ESL learning has been investigated by many previous researchers. The investigation of these studies has focused on different aspects of blog in relation to language learning and teaching. Most of the studies 
focused on the learners' perceptions and attitudes towards language learning using technology. For example, Hong et al. (2003) conducted a study among Malaysian learners on the success of technology and internet-enriched teaching and learning environment in moulding positive attitudes. The focus of the study was on the students' attitudes towards using the Internet as a learning platform. Data were collected via survey questionnaires. The findings of the study showed that the learners had positive attitudes towards using the Internet as a learning tool, adequate basic knowledge of the Internet, and illustrated the learning environment as supportive of using the Internet for learning. So, this study is significant as it focused on both teaching and learning aspects. Sun (2009) also conducted a study on the emerging themes characterize perceptions of participants' blog experiences. He focused on the learners' learning processes and learning strategies in voice-blog activities. The findings of the study proved that students improved a series of blog stages, including conceptualizing, brainstorming, articulation, monitoring, and evaluating, and used different types of strategies to deal with blog-related difficulties. In addition, the students perceived blog as a means of learning, selfpresentation, information exchange, and social networking.

In Arabic context, Al-Fadda and Al-Yahya (2010) investigated a study on the students' experiments of using blogs to encourage themselves to do pre-class reading assignment and reflections after class. They focused on students' attitudes towards the use of blogs. The findings of the study showed that there was a positive attitude towards the use of blogs for pre-class preparation and post-class reflections. Yet, considering the successful experience, it is vital to consider the size of the sample, students' educational level, and the type of reading assignment as well. Waely and Aburezeq (2013) explored pre-service Arabic language teachers' perceptions of using the blog as a learning tool, and the defects of collaborating via the blog. The findings of the study indicated that the participants perceived the course blog as a powerful application to improve their learning through facilitating active interaction with the instructor, peers and course content. Finally, (Zarei and Al-Shboul 2013) conducted a qualitative study on Jordanian EFL learners' perceptions towards language learning via blog. They found that the learners perceived the blog as an interesting and helpful learning tool since interacting via blog helped them improve their English language skills as well as their communication skill based on peer feedback.

In terms of students' perceptions towards using language learning blogs, Halic et al. (2010) also explored whether or not the use of blogs in a large lecture class would enhance students' perceived language learning. The findings of the study showed that while a majority of the students reported that blog enhanced their learning and led them to think about course concepts outside the classroom, fewer perceived value in peer comments. Furthermore, Sujud and Abd Rahim (2013) investigated the use of blog writing from the perspective of Korean learners learning the Malay language as a foreign language. The findings of their study showed that the blog helped the Korean students in learning the Malay literature. In addition, based on the findings of the study, the students became more motivated and confident in writing, especially in the Malay language. It is worth stating that Luo and Gao (2012) examined students' learning experiences in a set of structured micro-blog-based class activities in an exploratory study with a small sample size. The results of the study indicated that the structure provided by the instructor in the micro-blog activities allowed the learners to focus on the learning content as well as participate actively. The findings of their study also revealed that, after the class activities, the students had an increased positive attitude towards the educational use of micro-blog after the class activities.

A study by Hourigan and Murray (2010) focused on the pedagogical and support role of the teacher as well as considering the content of learners' reflective output throughout the course in the blog. The findings of the study showed that integrating blog into the language classroom is not a straightforward issue and it requires a great deal of groundwork beforehand in order to validate its inclusion in any type of academic course. In a sense, the teacher should ideally provide a structured and dependable guidance framework which learners can access in times of self doubt or difficulty. Furthermore, Ozkan (2011) carried out a study to provide a picture of a group of English Language Teaching (ELT) learners reflecting on their experience drawn from a blog facility used as a tool for sharing and commenting on peer performance in classroom setting. The findings of the study illustrated that blog experience had both positive and negative aspects. For the positive aspects of using blog, the findings showed that the Turkish EFL learners enhanced writing skill and self evaluation. In addition, they made use of the provided tool to reinforce peer to peer feedback and communication. On the other hand, negativity regarding the issues dealt with in this study tackled through continuous observation, training and awareness raising. Finally, a study by Zarei and Supyan (2014) showed that the learning management blog assisted the students to develop their independent learning interest as well as their motivation to use the English language learning materials in the learning management blog.

As it is obvious that the above studies have investigated the use of blog in education. Nevertheless, none of the above studies focused on how the LMB overcomes the learning time and space constraints that contribute to learner's language learning and language acquisition processes. Based on the data obtained from the need analysis carried out in the same course with 30 students, the researchers realised the students' problems in terms of learning in the classroom. The students voiced out that although the teacher provides them with some language learning materials related to the course, however they are still in need for extra learning materials in order to do their class assignments and tasks. In addition, they pointed out that the time limitation in the classroom never allows them to have sufficient discussion and interaction with the teacher as well as their classmates; therefore, they require more opportunities for sharing their knowledge and understanding with their classmates. Based on the students' feedback, attending the English course twice per week was not enough to improve their English skills. By studying the students' problems and needs, the LMB was created to overcome the learning time and space constraints that contribute to student's language learning and language acquisition processes. 


\section{Method}

Purposive sampling was applied to carry out this qualitative study. The sample involved 30 ESL students who attended the English Course at National University of Malaysia. The researchers used semi-structured interview and open-ended questionnaire in order to gain rich data to the objective of the study. The obtained data were analyzed qualitatively using content analysis.

\section{Findings}

The open-ended questionnaires were distributed to the students at the end of the semester. The students were given sufficient time in order to answer the questions patiently and clearly. The 30 students were also interviewed at the end of the semester. The interview questions were interrelated and interdependent to the questions asked in the open-ended questionnaire, because the researchers believe by recycling the questions from different perspectives, they will gain indepth and rich information to answer the research questions of the study.

In the open-ended questionnaire, the students were asked to share their opinions about the time they had for answering the questions in the LMB. According to the students' responses, the researchers realized that the students never had difficulties to answer the questions in the LMB as there were no learning time and space constraints for them to take part in the LMB activities. They all agreed that having sufficient time to answer the questions was a significant factor in order to think deeply and carefully about the questions. Based on their answers, they always had difficulties to answer the teacher's questions in the classroom due to the limitation of time. They mentioned that most of the times they were not given sufficient time to answer the teacher's questions, while they did not have such problems for answering the questions in the LMB. 27 students believed that learning via the LMB was a continuous learning process in which they were able to $\log$ in the LMB and start learning at anytime and anywhere. For example, one of the students mentioned that:

"As a matter of fact, it was very good opportunity for me participate in the blog at any time. No have specific time for participation in the blog make me more motivated to learn English. For the questions, I always tried to think very carefully and deep first and then post my answer in there. I have the chance to even discuss with others or get some information about the answer from the material in the menu before I posting my answers there. That was very good". (R6)

In the interview, the students were asked to share their opinions about the time they had for answering the questions in the LMB and in the classroom. All in all, their answers were in line with the feedback that the researchers received from the question in the open-ended questionnaire. The students believed that due to having sufficient time to answer the questions in the LMB, they were able to think carefully and post their answers and ideas. They mentioned that having insufficient time to answer the teacher's questions in the classroom was the problem that sometimes made them stressful.

"I think that is a good question. For me, I was very happy that we have enough time to read the questions and prepare myself to answer them in the blog. Actually, when I have enough times I can think more and also sometimes I can search about my answers also and then only post them in the blog. It was really helpful. I think sometimes we have these problems about timing in the class. When we want to write our ideas and answers in the class, we don't have many time or sometimes we feel stress.". (R15)

Moreover, the researchers asked about the students' feelings when they already knew that there was no time constraint for participating in the LMB activities. Based on the students' responses, the researchers found that the students were satisfied as there was no time limitation to share and post their ideas and views. 26 students stated that they became more interested and willing in participating in the LMB because they had the opportunity to reply to their friends' posts at any time. In addition, 4 students mentioned that they never felt nervous or uncomfortable since they had enough time to post their ideas and interact with their classmates in the LMB. Thus, they always took part in the LMB activities in a relaxed and calm mood which helped them learn more enthusiastically.

"For me, it was very good that we don't have any time limitation to write in the blog. Actually I opened the blog in my free time especially in the weekends to participate in the forum and also read the tips and also watch the speaking video. I was so happy and relax to do all these things in my free time". (R1)

In the interview session, the students were also asked to share their opinions regarding the time they had for answering the questions or posting comments on the LMB. All students strongly agreed that having no time limitation in the LMB for answering the questions, uploading their class assignments, posting their information, sharing their thoughts, and asking questions from each other helped them improve their language learning. Based on their responses, the researchers discovered that the students were happy and relaxed as they were not given any specific time to post or comment on the LMB.

According to the students' feedback, learning time and space constraints affect the process of learning. Referring to the classroom time which was four hours per week, the students never had enough time to ask their teacher about their problems and difficulties they had regarding their class assignments as well as English language skills. They mentioned 
that, having time limitation in the classroom, sometimes creates stress and tension. They believe that, limitations of learning time and space make them panic and stressful which leads them to feel uncomfortable and sometimes confused. Such problems disturb the process of language learning and language acquisition.

The students stated that they were able to answer the questions in the LMB patiently, carefully and cautiously. They always had sufficient time to think twice in order to share their ideas and thoughts with the peers in the LMB. In other words, all students agreed that the LMB reduced their stress and anxiety during the learning process.

"As for me, the time was always very good. Especially when there is a question in the discussion forum for us, I answered the question and I am able to take my long time to think about the answer. Nothing was push

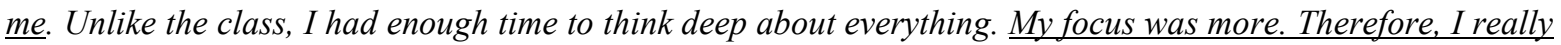
prefer to comment and share my opinions in discussion forum rather than the sharing my ideas in the class. It was more better and it give more time to think deep". (R9)

Another question in the semi-structured interview was formulated to find out the students' opinions about continuous learning in the LMB. 22 out of 30 students voiced out that learning via the LMB was more affective and helpful as compared to the traditional way of learning in the classroom. Based on the students' responses, by attending the English course for four hours, the learning process would not be continuous; while by using the LMB outside the class they were still involved in the language learning and language acquisition processes anywhere and anytime. They believe that, continuous learning is very helpful and make them more motivated to learn and acquire more knowledge. The students mentioned that the opportunity of forgetting lessons, tips, techniques and skills is more when the learning process is not continuous. According to the students' feedback, by having a non-stop learning environment such as the LMB, not only they are able to keep practicing the English language skills but also they remember the lessons, tips and significant points which were mentioned by the teacher in the classroom.

"In fact, when we learn continuously definitely it is more useful. For me, attending the class only two times per week isn't enough. Sometimes I forget some important lessons or things that my teacher teach me, so when I open the blog to practice, automatically I can remember those things which I forget. Even I can see that my friend post about those lessons also. So, it also will help me to practice again and more than two times in week. This is really good because I can always open the blog and improve my English". (R16)

The students stated that, by having no limitation with regard to learning time and space, they improved their English language learning and language acquisition due to the following reasons. They believed that they are more motivated to learn when there is no learning time limit or space barrier. Based on 3 students' opinions and feedback, they became more interested in learning English. According to them, learning time and space limitation cause some difficulties such as: not having enough time to get engaged in learning and acquisition processes, having less interaction and discussion with the teacher as well as the classmates, and losing interest and motivation.

"I can say that learning continuously is very useful. For example, by using the blog during this semester I really improve my English, because I have chance to use the blog and the contents to practice English language more. So, no need to wait only for the class and my teacher to learn. Have interaction continuously with my friends really help me to improve my English skill. This semester I become more motivated to learn English if I compared to the previous semester. I want to say that I used the blog many times per week in this semester, so I learn a lot of things more than learning in the class". (R24)

The next question was set in order to find out how the students felt when they already knew that there was no time constraint for participating in the LMB activities. Based on the students' responses the researchers found that all students were satisfied and happy as they were not given any specific time to answer the questions in the LMB, discussing and interacting with others, sharing their ideas, posting their tasks, and making use of the provided language learning materials in the LMB. According to the feedback given by the students, it can be concluded that having no learning time and space limitations made them feel more confident, motivated, relaxed and convenient. They stated that as long as they were already informed that there was no specific time for participating in the LMB activities, they never felt anxious, stressed, being in a hurry to come up with the answers to the questions or be engaged in the interaction. They all believe that the pressure of time always makes them feel uncomfortable and it will lead them not to think deeply and carefully about the questions, topics as well as the lessons. Here is one example of what the students mentioned:

"In fact, because we don't have specific time for post our comments and assignments. it helped me to do my assignments more carefully. Also, help me to share my problems with my friends in the discussion forum before submit to my teacher and even before to upload my assignments in the blog. I was more confident when I can learn from the learning materials and also from my classmates' ideas because at any time we were free we log in and learn something. The time was not less to do all things". (R19)

Another question in the open-ended questionnaire was formulated in order to find out whether or not the students were stressed while answering the questions in the LMB. By receiving the students' responses, the researchers found that the 
students were never tense or anxious while participating in the LMB activities because there was no time limitation. They were able to discuss their class assignments and tasks with peers in their free time and improve their writing and tasks. Some of the students believed that feelings of stress and panic appear when they face lack of time.

"Actually, I was never stress or nervous when answering the questions in the forum. I think this is because I have enough time to think about the answers to the question in the blog. So, I post my responses in the blog in good mood in my room patient. Sometimes I got help from the tips and videos in the blog to answer more better also. Because I had enough time to read learning materials and then share my idea in the blog to improve my informations and also my outline". (R7)

27 out of 30 students mentioned that they get stressful and tense when they want to answer the teacher's questions in the classroom due to having only a few minutes to come up with the answers. According to them, feelings of stress and anxiety affect their learning processes.

"I think it is very good idea that there no specific time to answering the question in the blog. So I was always relax and comfortable to think and reply to all questions. In the class sometimes I get very stressful when I want to answer to teacher because he don't give me a long time to think twice. Also, I prefer to learn by blog more than the class because I never stressful". (R11)

In the interview session, the students were also asked a question regarding their feelings while answering the questions about their class assignments in the LMB. 24 students agreed that they felt comfortable and relaxed to answer the questions in the LMB. They all believe that answering the questions in the classroom makes them stressful especially when the teacher asks them to answer a question orally. Based on their feedback, the feelings of stress and anxiety appear when they face lack of time to think of the answers and come up with the answer. They believe that answering the questions in the LMB did not make them stressful because they always had time to think deeply and search for the answers to the questions. 6 students voiced out that they become stressful in the classroom while answering the questions because they are shy to speak in the classroom. Feeling of shyness was the reason why they became stressful while answering the questions to the teacher. They agreed that answering the questions in the LMB never made them anxious because they felt very relaxed to think about the answers and post their ideas. One of the students' answers is as following:

"Well, I think participating in the blog never make me stressful. The reason can be the environments or also time. Sometimes I participates in the blog in my room, coffee shop or even library. I like the quite environment when I want to share my ideas in the blog. Also, there is no time pressure for me to answer the questions or also to share my ideas. But in the class, I sometimes feel stress because of the teacher presence and even my classmates”. (R13)

Eventually, based on the students' feedback via the open-ended questionnaire and semi-structured interview, it is obvious that the students did not feel anxious or stressed while participating in the LMB activities due to having sufficient time. They felt comfortable and relaxed to think deeply and post their opinions and task on the LMB, since there was no specific time allocated for their participation to make them stressful. In other words, they had the freedom of choosing their own times to post their ideas and tasks during the semester as well as getting involved in the discussion with their group members. Based on the responses given by the students, learning in the classroom sometimes is stressful due to being shy or having insufficient time to get prepared to answer the teacher's questions. In addition, the students participated in the LMB activities and made use of the language learning materials as well as the interaction due to having sufficient time.

\section{Discussion of findings}

The students made use of the scaffolding facilities by reading the language learning materials at any time. By referring to Vygotsky's constructivism theory (1978), scaffolding refers to a kind of support that can be provided by both teachers and students. The scaffolding assists students to gain their learning objectives at their current level of ability. The LMB environment played as a scaffolding system in which the students exchanged their experiences and thoughts with each other in order to improve their understanding. According to the students' feedback, due to not having the limitations of time and space, the students made use of the scaffolding in a relaxed mood at anytime anywhere. They learned independently outside the classroom by using the language learning materials offered in the LMB. The processes allow the students to be active participants in developing their own understanding of important concepts and achieve their learning goals (Peters et al. 2003). Students can learn best when they can discuss and exchange their understanding with others. As Vygotsky believed that learning happens within the ZPD, and the purpose of learning is to build new abilities. He also asserted that social-recognition development and stated that social interactions are the basis of the internalization process. The student's purpose is to transform social knowledge into individual knowledge.

Based on the students' responses, the time given for the English course was not sufficient for them to improve their English language skills. They believe that the limitations of learning time and space do not allow them to have sufficient amount of sharing ideas and suggestions in the classroom. That is in line with Bloch (2004) who stated that 
"blog enables individuals to express their thoughts at their own pace and in their own space so that, in contrast to traditional classroom settings, blog learners do not have to compete with their classmates for the instructor's attention".

By providing sufficient learning time and the opportunity of having a continuous learning system, the students enhanced their language learning and language acquisition processes. Black (2005) believes that "Unlike traditional teaching where the instructor or a few students may dominate the discussion, the blog allows all voices to be heard. Even those students who may be intimidated by speaking in front of their peers, or those who need more time to respond are easily able to express their thoughts more freely and descriptively". Krashen (1987) believes that comprehensible input is a sufficient condition for language acquisition and he also asserts that no language will be acquired in the presence of the affective filter. This means it is easier for the student to acquire a language when she/he is not tense, nervous, or board. If the students feel nervous or tense during the learning process, they will learn neither the contents nor a new language, even if the input is comprehensible. Higher affective filters prevent them from successfully processing input. In other words, low filter can help the learners become more open to the language input. The strength of the filter itself is determined by affective factors of learner anxiety, self-confidence, and motivation.

By making use of the comprehensive inputs provided in the LMB the students learned and acquired the language. They were involved in the learning and acquisition processes comfortably. As it is mentioned earlier, the students agreed that sometimes they feel stressed out while learning in the classroom due to lack of time. Based on the students' feedback, some of the students were not feeling comfortable in the classroom because they felt shy or less confident to speak in English Language because of poor speaking skill. The feeling of anxious and stress can affect the whole learning process. On the other hand, they believe that they never felt stressful and board while learning via the LMB and sharing their ideas and tasks in the forum. According to their responses, they were satisfied to have enough time to answer the questions in the LMB, share their ideas, and make use of the language learning materials. Hanson-Smith (2001) stated that "blog provides a safer and more relaxed environment for language learners, especially for the shy or less confident ones". Based on Maslow's hierarchy of needs (1943), safety refers to shelter, including a sense of familiarity and comfort. According to him, without safety, people feel worried and uncertain. Whereas learning through online platforms such as the LMB, potentially eases some stressful factors found in a traditional classroom setting such as: limitation of flexibility with time and location as well as boundary of learning space. According to the obtained data, the students were relaxed and comfortable while using the LMB as they were not tense or worried.

\section{Conclusion}

The results of the study showed that the LMB played an important role as a language learning platform outside the classroom. The scaffolding language learning materials in the LMB assisted the students to enhance their language learning and language acquisition processes and made them independent learners. Having sufficient learning time was one of the significant factors that helped them make use of the provided language learning guides and interact with one another in the LMB. Due to not facing learning time and space limitations, the students improved their knowledge and information in a peaceful online platform. Hence, integrating the LMB into the English language classes is very helpful and supportive in order to compensate the constraints of learning time and space as well as enhancing students' language learning and language acquisition processes.

\section{References}

Al-Fadda, H. Al.-Yahya, M. (2010). Using web blogs as a tool to encourage pre-class reading, post-class reflections and collaboration in higher education. US-China Education Review, 7, 7, 100-106.

Black, A. (2005). The Use of asynchronous discussion: Creating a text of talk. Contemporary Issues in Technology and Teacher Education, 5, 1, 5-24.

Bloch, J. (2004). Second language cyber rhetoric: A study of Chinese L2 writers in an online usenet group. Language Learning \& Technology, 8, 3, 66-82.

Brian, A. (2006). Web 2.0. A new wave of innovation for teaching and learning? Educause Review 41,2.

Campbell, A. P. (2003). Weblogs for use with ESL classes. The Internet TESL Journal 9(2).

Downes, S. (2005). E-learning 2.0. eLearn Magazine. Trade Journals.

Duber, J. (2002). Mad blogs and English(men). TESL-EJ, 6(2).

Halic, O., Lee, D., Paulus, T. \& Spence, M. (2010). To blog or not to blog: Student perceptions of blog effectiveness for learning in a college-level course. The Internet and Higher Education 13(4). 206-213.

Hanson Smith, E. (2001). Computer assisted language learning. In R. Carter, \& D. Nunan (Eds.), The Cambridge guide to teaching English to speakers of other languages. Cambridge, UK: Cambridge University Press. 107-113.

Hong, K. S., Ridzuan, A. A., \& Kuek, M. K. (2003). Students' attitudes toward the use of the Internet for learning: A study at a university in Malaysia. Educational Technology \& Society 6, 2, 45-49.

Hourigan, T. \& Murray, L. (2010). Using blogs to help language students to develop reflective learning strategies: Towards a pedagogical framework. Australasian Journal of Educational Technology, 26, 2, 209-225.

Kabilan, M. K., Ahmad, N. \& Zainol Abidin, M., J. (2010). Facebook: An online environment for learning of English in institutions of higher education? The Internet and Higher Education, 13, 4. 
Krashen, S. D. (1987). Principles and practice in second language acquisition. Prentice-hall International.

Luo, T. \& Gao, F. (2012). Enhancing classroom learning experience by providing structures to microblog-based activities. Journal of Information Technology Education: Innovations in Practice, 11, 199-211.

Maslow, A. H. (1943). A Theory of human motivation. Psychological Review, 50, 4, 370- 396.

Mazman, S. G. \& Usluel, Y. K. (2010). Modeling educational usage of facebook. Computers \& Education, 55, 2.

Ozkan, Y. (2011). Blog in a teaching skills course for pre-service teachers of English as a second language. Australasian Journal of Educational Technology \& Society, 27, 4, 655-670.

Pasfield-Neofitou, S. (2011). Online domains of language use: second language learners'experiences of virtual community and foreignness. Language Learning \& Technology, 15, 2.

Peters, J., Cornu, R. L \& Collins, J. (2003). Towards constructivist teaching and learning (Report on research conducted in conjunction with the learning to learn project). Magill: University of South Australia.

Sujud, A. \& Abd Rahim, N. (2013). Learning through blog. Australian Journal of Basic and Applied Sciences, 7, 1, 191-198.

Supyan, H., Norizan, A., R. \& Dalia, S. Q. (2009). Developing blogs: New dimension in language teacher education. Paper presented Teaching and Learning of English in Asia (TLEiA Three), Orchid Garden Hotel. Brunei Darussalam.

Thorne, S. \& Payne, J. (2005). Evolutionary trajectories, internet-mediated expression, and language education. Calico Journal, 22, 3, 371-397.

Vygotsky, L. S. (1978). Mind and society: The development of higher mental processes.

Waely, S. A., \& Aburezeq, I. M. (2013). Using blogs to facilitate interactive and effective learning: perceptions of preservice Arabic teachers. Journal of Language Teaching and Research, 4, 5, 975-985.

Zarei, N. \& Al-Shboul, Y. (2013). Participating in a blog: Jordanian EFL learners' voices. English Linguistics Research, 2, 2, 53-59.

Zarei, N. \& Supyan, H. (2014). Impact of learning management blog on students' language learning and acquisition. GEMA Online Journal of Language Studies, 14, 3, 51-63. 